\title{
LO CONSABIDO: MOSTRACION DE LA EXPERIENCIA
}

\author{
Gastón Gainza *
}

En un sugerente estudio, publicado hace ya varios años, mi amigo y colega Guillermo Araya legitimó la existencia de la función mostrativa del lenguaje, a partir de un lúcido análisis de la Teoria del lenguaje de Karl Bühler (1). La importancia de este aporte teórico no sólo ha de verse en relación con una comprensión más adecuada de lo que es el lenguaje, sino también con una más estricta descripción de las lenguas históricas, toda vez que hace posible -como sustento metodológico- el estudio riguroso y pleno de un sistema lingüístico (2). Intentaré demostrar brevemente en este trabajo cómo se encarna el principio postulado en la morfología de la gramática española, sin perjuicio de que la validez de su aplicación pueda verse igualmente comprobada en los estudios Iexicogenésico, semántico y sintáctico de la lengua española.

Para establecer desde el comienzo de esta exposición las diferencias identificadoras, es conveniente partir de un exa-

* Creada originalmente para ser presentada como ponencia en el III Congreso de la Asociación de Lingüística y Filología de América Latina (ALFAL), fue leída, posteriormente, en el I Simposio de Lingüística y Filología celebrado en Valparaíso (Chile), en noviembre de 1971 . men del género gramatical en cuanto característica de clase de los nombres en las lenguas que lo sutilizan como rasgo distintivo formal (3). Su valor originario está vinculado a un criterio taxonómico de los objetos de la realidad y sus correspondientes clases, aprehendido intersubjetivamente para los fines de la comunicación.

Con la evolución del pensamiento humano, tal principio clasificador, ha experimentado una notable reducción semántica. Es por eso que en español podemos captar sólo un muñón de su antigua efectividad en la diferenciación de sexos que se manifiesta genéricamente a través de algunos sustantivos que representan clases de objetos sexuados. Su misma debilidad y precariedad está demostrada por la existencia de los sustantivos llamados epicenos y comunes los que, aun cuando representan clases de objetos caracterizados por dicha particularidad biológica, no denotan la distinción a través de su marca formal. Pero, por otra parte, su virtualidad y latencia hacen posible que, mediante un proceso de animización, la distinción opere en sustantivos que representan clases de objetos no sexuados. En relación con esto habría que examinar, también, los recursos lexicogenésicos y sintácticos que concurren, en multitud de casos, a marcar la diferencia o a establecer lúdicamente una 
distinción aparente.

Por lo expuesto hasta aquí puede estimarse que el valor nocional originario del género se hallaba esfuminado ya en la lengua latina y no puede constituir, por tanto, un rasgo sémico identificador de los sustantivos en español. En esta lengua, su papel ha devenido en expresión de las relaciones sintácticas de concordancia que el sustantivo impone sobre otras clases de palabras en el sintagma. Lo que importa para los fines de mi trabajo es destacar que el valor es secundario, aunque sea el único legítimamente aprehensible en la descripción del español (4). Dicho lo mismo de otra manera: que al género gramatical sea en español la marca de la concordancia con el sustantivo, sólo es posible por su carácter originario de diferenciador semántico en la representación de clases de objètos. De aquí se infieren, necesariamente, dos cosas: de una parte, que el género está adscrito a la magnitud morfológica llamada sustantivo; de otra, $-\mathrm{y}$ en íntima conexión con la anterior-, que su función es representativa (5).

Llama la atención, a diferencia de lo que se ha dicho sobre el género, que en el vasto campo léxico de los signos mostrativos no exista un rasgo formal distintivo que denote su función deíctica. La razón es simple: tal carácter semántico se aprehende sin dificultad en la impleción significativa de los mostrativos. Por eso, dichos signos se organizan, en cambio, en paradigmas léxicos constituidos en base de las diferentes intuiciones deícticas que configuran la comunicación lingüística.

Estoy hablando de la existencia de órdenes mostrativos diversos. Procuraré demostrar esto en lo que sigue, pero antes debo atender a una cuestión de principios insoslayable.

Si se examinan los paradigmas de los signos mostrativos del español. podrá apreciarse que en algunos de ellos ( el $\sim$ la $\sim l o \sim$ los $\sim$ las; este esta $e s t o \sim e s t o s \sim e s t a s$; mio mia $\sim$ Mi mios mias mis, etc.), existe la variación genérico-numérica; en otros, sólo la numérica (quien quienes; tal tales; $l e \sim$ les, etc.) $y$ en otros, ninguna ( $d o n d e \sim \mathrm{qu} \mathrm{i} \sim a h i \sim a l l i \sim$ cuando ahora $\sim$ entonces, etc). No tiene importancia para los fines que persigo el entregar sólo algunos paradigmas, y de éstos no todas las variantes en uso.

Los mostrativos capaces de alternancia formal de género y/o número, la evidencian en virtud de su relación deíctica situacional con el sustantivo que representa la clase a que pertenece el objeto mostrado. En el entorno, la deixis no apunta directamente al objeto; su significación indica la designación lingüística nominativa o representativa que aprehende conceptualmente la clase a que pertenece el objeto, y que alienta de modo virtual en el proceso de comunicación. Por lo demás, esta particularidad de la función mostrativa la integra definitivamente como dimensión semántica del lenguaje (6).

En el contexto la relación es absolutamente diáfana. Ya sea por la dependencia directa de un sustantivo que les impone su concordancia (esta CASA tuya, algunos LIBROS mios) o por la anáfora (aquéllas cuyo vuelo refrenaban/ tu hermosura y mi dicha al contemplar. BECQUER, Rimas, LIII), la variación formal viene impuesta o por la concordancia o por la mención precedente o subsecuente de un sustantivo.

Aún es conveniente establecer otra precisión: por lo menos, como una ojeada rápida, toda vez que su examen en profundidad será obje to de otro estudio. Se trata de la función a que pertenecen los morfemas de la magnitud morfológica verbo; por lo pronto, es inevitable señalar que la persona y el tiempo constituyen semas deícticos.

Pues bien, permítaseme decir por ahora sólo que el verbo no es una clase de signos de la función mostrativa -como lo son claramente, en cambio, los llamados pronombres y adverbios-, y que la existencia de semas deícticos en su estructura está al servicio de la autonomía sintáctica en una lengua como la española (7).

Ahora puedo volver a mi objeto fundamental: distinguir órdenes diversos en la mostración. Como quiera que la función mostrativa se aprehende en la situación comunicativa concreta, es metodológicamente imprescindible recurrir a ella para distinguir la especificidad funcional de su significación. 
Los factores que el signo pone en relación en toda situación comunicativa concreta son tres:

1) Un hablante locutor o emisor, que puede mostrarse a sí mismo solo (yo) o integrando un conjunto (nos-otros). (La existencia de un locutor múltiple -el coro de la tragedia, por ejemplo-es teóricamente desechable en el habla normal. La comunicación a través de un enunciado lingüístico une dos subjetividades; esto significa que quien habla articula su mensaje desde un sistema psicofísico individual, único e inintransferible.Por lo mismo, la decodificación del mensaje -aunque haya sido captado por diversos receptores- es privativa también de cada sistema psicofísico. Esta es la impronta más relevante del lenguaje) (8).

2) Un hablante auditor o receptor, que puede mostrarse como uno (tú $\sim$ usted) o como un conjunto (vosotros ustedes); en español, esta mostración permite -en ciertas áreas y en determinados niveles- distinguir, además, el grado de familiaridad que existe entre el auditor y el locutor. (En Chile, la oposición tú/usted, en el singular; asimismo el "vosco": uso de vos como apelativo singular).

3) Una circunstancia vital que supone, de un lado - e independientemente de las personas mencionadas-, la situación témporo-espacial del acto de la palabra, y de otro $-\mathrm{y}$ en íntima vinculación con quien habla-, la situación histórico-cultural evidenciada en el punto de vista o experiencia en que el locutor funda la comunicación. El tiempo y el espacio son ajenos a los interlocutores; éstos deben asumirlos intuitivamente a partir de un ahora y de un aqui correspondientes a la dimensión témporo-espacial del yo que habla. La experiencia, en cambio, es subjetiva y tiene su arraigo en la persona histórica del locutor, quien la orienta, intuitivamente también, desde un así. La distinción entre la deixis témporo-espacial y la indicación de experiencia es, por tanto, cualitativa. Esto se comprueba cuando se constata que en la indicación espacial cabe distinguir entre el lugar del yo (aquí), del tú (ahi) e, incluso, de la tercera persona (alli); en la mostración de tiempo se da, también, la posibilidad de oposición entre ahora y entonces, en la que este último signo denota un desplazamiento tanto hacia el pasado como hacia el futuro en la intuición temporal. En cambio, asi -que es el mostrativo de la experiencia- no tiene opósito: quien habla sólo conoce su experiencia propia; la de su interlocutor, a lo más, puede ser supuesta. Por otra parte, la experiencia es siempre un resultado acumulativo.

La distinción del espacio en relación con las personas de la situación comunicativa concreta parte de un hecho incuestionable: el lugar que la persona que habla ocupa en el espacio es incompartible con el que ocupa el auditor, y el de ambos-obviamente-, con el de quien no está en la situación misma. El tiempo, en cambio, es una dimensión de la realidad que locutor y auditor comparten normalmente, i.e., no hay un ahora para el yo y otro para el tú. Esto pareciera aproximar la deixis temporal a la indicación de experiencia -lo que, por otra parte, puede ser estimado como natural, en la medida en que la experiencia es historia e historia es tiempo vivido-: sin embargo, no conviene metodológicamente identificar ambas dimensiones intuitivas, toda vez que la experiencia (resultante del proceso dialéctico vivido por todo individuo entre su ontogénesis y la filogénesis de su medio (9); por eso la experiencia es vividura), es tan intransferible y subjetiva como el proceso mismo de organización del enunciado lingüístico en el locutor y el análisis para su intelección en el auditor, a que me referí más arriba. La temporalidad se revela, por el contrario, como objetiva y mensurable en común.

En resumen: el espacio es una objetividad no compartible: el tiempo es una objetividad compartible, y la experiencia es una subjetividad que, sólo mediante un proceso especial, puede ser objetivada por el locutor en el enunciado de su comunicación lingüística.

Ahora bien, como la experiencia es subjetiva el hablante puede someterla a un juego intuitivo que consiste en atribuirla al auditor. En ese momento, se convierte en lo consabido de la comunicación: a partir de ella se orienta el punto de vista con que es emitido el enunciado lingüístico. Materialmente, este proceso se realiza como adecuación de lo que se dice al destinatario. (Piénsese, por ejemplo, en que el decir no es 
ni puede ser el mismo cuando el destinatario es el conjunto de estudiantes del aula que cuando es un conjunto de amigos en la cafetería del campus; tal diferenciación se funda en el punto de vista. A veces, también lo físico del decir fuerza -en concomitancia con la circunstancialidad y la calidad del auditor- la adopción de un determinado punto de vista: el habla confidencial con una hija o con la amada supone una línea melódica distinta de la que soporta una intervención en el Instituto; en esa diferencia radica un punto de vista que exige un léxico determinado y un ordenamiento sintáctico específico. Existe una cultura lingüística que consiste, precisamente, en saber adecuar el uso del lenguaje al interlocutor en cada circunstancia concreta. Esta cultura se mide en términos de eficacia social, y tiene mucho que ver con la influencia que la persona puede ejercer sobre su medio).

De lo dicho hasta aquí se desprende que la reducción analítica practicada por Bühler, en orden a establecer tres coordenadas de orientación básica del hablar (ego, hic, nunc), si bien cumple una función esclarecedora muy importante, resulta insuficiente para el estudio exhaustivo de los mecanismos de formalización a que el hablante recurre para entrar en comunicación lingüística (10). Deja sin aclarar el rol que desempeñan en la lengua los llamados adverbios de modo y el morfema modal del verbo.

En la medida en que un hablante es un ente histórico dotado de memoria, orienta su habla -como su actividad vital toda- a partir de un propósito fundado en su experiencia. A su vez, ésta se le aparece como posible y factible en otro ser como él. Al entrar en comunicación, por tanto, evalúa la probabilidad de experiencia compartida $y$ establece un ordenamiento intuitivo gradual que se manifiesta en la elección de normas. Pero, además, muestra su personal punto de vista sobre lo que enuncia a través de la oposición modal del verbo y/o de los mostrativos de modo. Esto es posible porque $l o$ consabido se halla inserto en el parasistema como dimensión semántica mostrativa de la primera articulación (11).

Como aplicaciones concretas de esta distinción en la descripción gramatical, me limitaré a enunciar dos de los temas en que su productividad permite una fecunda comprensión de los fenómenos lingüísticos examinados.

En primer lugar, en el estudio de la magnitud morfológica verbal, que puede ganar en sistematicidad gracias a la identificación de una variedad deíctica modal. El modo en el verbo está al servicio de la oposición 'certeza/no certeza' de la significación total del sintagma; por este motivo, deben descartarse como formas modales los llamados inadecuadamente "modos" infinitivo e imperativo. En cuanto a la distinción entre indicativo y subjuntivo (y potencial en algunas doctrinas, como la de la Real Academia), debe ser descrita de nuevo para deslindar, ante todo, la oposición estrictamente modal (debe asistir/debiera deberia asistir), de las exigencias tradicionalmente estudiadas como “consecutio temporum' (me pidió que viniera, donde en el casillero de viniera no cabe ninguna de las formas caracterizadas como 'indicativo', aunque la oposición semántica del modo no sea allí pertinente). Que la marca de la oposición sea el sema 'certeza', se debe a que la mostración modal indica lo consabido, la experiencia en que el hablante funda el punto de vista de su decir. Por lo demás, esta misma característica semántica mostrativa juega un papel importante en la adjetivación atenuada mediante un como antepuesto (parecía COMO resuelto: una noche COMO siniestra) que no por casualidad entra en la zona de la ironía (12).

En segundo lugar, y en íntima relación con el papel del adjetivo, puede contribuir a aclarar el rol que en el léxico desempeña el sufijo -mente que, con alguna razón, puede ser llamado morfema de modo. Es un hecho conocido que ya en latín el sustantivo mens, mentis fue utilizado para construir locuciones adverbiales (13). Tal uso se generalizó en las lenguas romances (14). La explicación de que pase a significar modalidad ha de verse en su etimología: la raíz * men 'pensar'. La mostración de lo consabido es el resultado del proceso dialéctico entre la representación y la intuición; en ella se materializa la historicidad del hombre. La significación modal es deudora de la vividura humana puesta en juego cada vez que se habla: la memoria y la intención coordinadas en el enunciado lingüístico de la comunicación 
(15). Es por eso que resulta tan atractivo iniciar desde el establecimiento de la función mostrativa de lo consabido un nuevo estudio del papel que en la lengua desempeña el adjetivo, toda vez que adjetivar es denotar cualidades y éstas son "modalidades" atribuidas a los objetos de las clases representadas por los sustantivos. Baste mencionar que son adjetivos los que, normalmente, se unen al sufijo - mente para formar los llamados adverbios de modo cualitativos. (Que en el sufijo subsista el morfema de género -que exige que el adjetivo que entra en sintagma fijo con él adopte, si es del caso, la terminación, $-a$ del femenino-, constituye un motivo de análisis que procuraré realizar en otro trabajo).

En conclusión, a los factores constitutivos de la circunstancia vital en que siempre se da todo enunciado lingüístico (hic y nunc de Bühler), debe agregarse un sic que muestra la experiencia individual del hablante sobre la que intuye lo consabido predecible para una comunicación eficaz. Tal experiencia define al hombre que habla en una historicidad permanente, ineludible y específica de la condición humana. Lo consabido es la intención comunicativa inducida de esa experiencia. En tal componente de la comunicación no sólo debe reconocerse la relevancia que implica saber si el interlocutor maneja el mismo código y si lo maneja de una manera aproximada a la del que habla, sino también la que supone saber -0 pronosticar - si comparte o no los puntos de vista o perspectivas del discurso y, por lo mismo, su vividura materializada en las alusiones o modalidades del decir.

Por tanto, los órdenes de la mostración son cuatro: la persona, el modo, el tiempo y el espacio. Cada uno de ellos configura áreas léxicas propias. Además, los tres primeros materializan los morfemas verbales y hacen posible la capacidad de doble campo: conditio sine qua non de la autonomía sintáctica.

\section{NOTAS}

1) K. BUHLER, Teoría del lenguaje. Madrid 3a. ed., 1967, Rev. de Occidente, Selecta, 18. Trad. por J. Marías; pp.622. Y G. ARAYA, "Dimensiones semánticas del lenguaje", en Mapocho II, No. 1 (1964), 179-193.

El término "lo consabido" lo he tomado de mi maestro Eleazar Huerta, quien, con sus finos y perspicaces análisis, me introdujo en el campo de la mostración lingüística.

2) Cf. G. ARAYA: "Es un problema de empiria y relacionado con cada idioma concreto o con familias de lenguas llegar a determinaciones más detalladas acerca de cómo se dan en los tipos de palabras las funciones dominantes", art. cit. p.186.

3) Vid. A. MEILLET, Linguistique historique et linguistique générale 2 tomes, Paris, 1948 y 1951. Libr. Anc. Honoré Champion et libr. C. Clincksieck; Vol. I, pp.199-210 y 211-229, y Vol. II, pp.24 y ss. J. VENDRYES, El lenguaje. Introducción lingüística a la historia. Barcelona, 2a. ed., corr. y aum., 1953. Edit. Cervantes. Trad. de M. de Montoliú y J.M. Casas; pp.125-132. J. MATTOSO CAMARA JR., Principios de Lingüística General Rio de Janeiro, 3a. ed., rev. y aum., 1959. Livr. Acad.; pp.154-165. Cf., asimismo, G. ARA-
YA, "Hombre y lenguaje", en Mapocho. I, No.2 (1963), 68-71.

4) Aunque la Academia pone el énfasis en el valor taxonómico del género-y la siguen en esto las gramáticas escolares-, A. Bello, en cambio, lo estudia como función sintáctica. Vid. R.A.E., Gramática de la lengua española. Madrid, nueva ed., reformada, 1931. Espasa-Calpe; pp. 12-18, y A. BELLO y R. CUERVO. Gramática de la lengua castellana. Buenos Aires, 7a. ed., 1964. Sopena; pp.37-39.

5) En otro estudio intento demostrar que la relación sintáctica entre sustantivo y verbo (en cuanto formantes oracionales sujeto y forzoso, respectivamente) debe entenderse como de interdependencia, precisamente porque no es el género la marca que participa en ella. Cf., además, G. GAINZA, "Notas a la Clasificación de las proposiciones de A. Bello", en Estudios Filológicos, 2 (1966), $131-160$.

6) G. ARAYA: "la mostración intrínseca se hace impletiva al conjugarse con una "cosa", un objeto espacial o temporal, percibido por nuestros ojos o por nuestros oídos", (Dimensiones p. 187). Yo preferiría decir que la impleción se consigue en el momento en 
que la mostración se coordina con la representación de la clase a que pertenece el objeto indicado. Por cierto, la perspectiva de Araya está centrada más bien sobre el contorno de la acción verbal cuando formula la observación que he transcrito.

7) Es, funcionalmente, un hibrido. Cf. G. ARAYA, Dimensiones, p.186 y G. GAINZA, art. cit.pp.134 y ss.

8) Vid. E. BENVENISTE, Problèmes de linguistique générale. Paris, 1966. Gallimard; pp. $56-62$ y $75-87$.

9) Vid. A. SCHAFF, "Langage et réalité", en E. BENVENISTE, N. CHOMSKY et autres, Problèmes du langage. Paris, 1966. Gallimard; pp. 153-175. Dice Schaff: "Car ce que l'homme perçoit et la façondont il perçoit, comme ce que l'homme connait et la façon dont il le connait, dépend du type d'expérience (accumulé au cours de la phylogènese et de l'ontogènese) dont il dispose", p.171. (El cursivo es nuestro).

10) Vid. K. BUHLER, op. cit.; pp. 137-141 y 169-194. "Todo lo que es lingüísticamente deíctico coincide en que no recibe en cada caso su impleción y precisión significativa en el campo simbólico, sino en el campo mostrativo del lenguaje: y solo en él puede recibirlas (p.139). Al finalizar el No.20, en que examina las funciones del artículo, trata de "la deixis del 'así' como paralelo" (pp.462-464), pero no integra el eje que propongo aqui dentro de las orientaciones permanentes de la situación comunicativa.

11) La teoría de las dos articulaciones del lenguaje: en A. MARTINET, La lingüistica sincrónica. Estudios e investigaciones. Madrid, 1968. Gredos; pp.9-41. En cuanto al rol de lo consabido en la lengua, véase $\mathrm{E}$. HUERTA, "La mostración y lo consabido. (Un alcance a S. Fernández)", en Lengua, literatura, folklore. Estudios dedicados a $R$. Oroz. Santiago, 1967. Fac. de Fil y Ed. Univ. de Chile; pp.227-231.

12) C. G. GAINZA, “" 'Es como mucho...' en el español coloquial de Chile", en Estudios Filológicos, 4 (1968), 60-72.

13) Vid. A. ERNOUT et A. MEILLET, Dictionnaire étymologique de la langue latine. Histoire des mots. París, 4e. éd., $2 \mathrm{e}$. tirage augm. de corrections nouvelles, 1967 Klincksieck; p.397.

14) Cf. W. MEYER-LUBKE, Romanishes Etymologisches Wörterbuch. Heidelberg, 3. vollständig neubearb. Aufl., 1935. Carl Winters Universitäsbuschhandlung: "Das Wort mente dient fast überall zur Bildung der Adverbien", p.451. Vid., asimismo, S. FERNANDEZ, "A propósito de los diminutivos españoles", en Strenae. Estudios de filologia e historia dedicados al Prof. García Blanco, Salamanca, 1966, Acta Salamanticensia, T. XVI, p.186.

15) Cf. A. ERNOUT et A. MEILLET: "Terme tres général de la racine* men - "penser” et qui désigne, par opposition a corps, le "principe pensant, l'activité de la pensée", l'esprit, l'intelligence, la "pensée" (sens abstrait et concret, e. g. Vg., As. 1, 676...), par suite "1" intention", loc. cit. p. 396. 